\title{
Entrevista a Sara Makowski \\ Comunicar la diferencia: un proyecto radial realizado en México por personas con experiencias de internamiento psiquiátrico
}

\author{
Communicating the difference: a radio project carried out in Mexico by people \\ with experiences of psychiatric internment. Interview with Sara Makowski
}

http://dx.doi.org/10.22235/d.v0i26.1387

Mercedes Clara

Mercedes Clara Universidad Católica del Uruguay

Montevideo, Uruguay mercedes.clara@ucu.edu.uy

Recepción: 04/05/2017

Aceptación: 25/05/2017

$1::$ Sara Makowski visitó la Universidad Católica del Uruguay el 9 de junio de 2016. En esa oportunidad ofreció una charla titulada "Comunicación y diferencia. Una reflexión en torno a las narrativas de la alteridad desde una propuesta de comunicación para la inclusión social".

\section{RESUMEN}

Una radio en el jardín de la universidad. Un lugar donde personas con distintos trayectos biográficos se encuentran para vivir una experiencia de comunicación. Una polifonía de voces que crea lazos, genera diálogos, rompe estereotipos y produce inclusión social. Sara Makowski, socióloga y doctora en antropología, coordina la propuesta multimediática Radio Abierta, en la Universidad Autónoma Metropolitana de México, que es llevada adelante por personas que han experimentado sufrimiento mental. En esta entrevista, realizada en el marco de su visita a la Universidad Católica del Uruguay', Makowski compartió los aprendizajes, alcances y desafíos que implica "comunicar la diferencia".

Palabras clave: inclusión, comunicación alternativa, salud mental, radio universitaria, Radio Abierta

\section{ABSTRACT}

A radio in the garden of a college. A place where people with different biographical paths meet to live a communication experience. A polyphony of voices that creates bonds, generates dialogues, breaks stereotypes and produces social inclusion. Sara Makowski, a Sociologist and Doctor in Anthropology, coordinates the multimedia project Radio Abierta, in the Universidad Autónoma Metropolitana de México, which is carried out by people who had experienced mental suffering. In this interview, made during her visit to the Universidad Católica del Uruguay, Makowski shared the learnings, scope and challenges of "communicating the difference".

Keywords: inclusion, alternative communication, mental health, university radio, Radio Abierta 


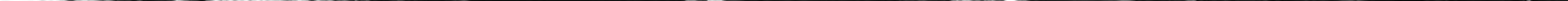




\section{¿Cuándo y cómo nace Radio Abierta?}

Radio Abierta se empezó a fraguar en el año 2008 cuando, de forma azarosa, me enteré de la existencia de $L a$ Colifata y Radio Nikosia ${ }^{2}$ mientras realizaba una investigación socioantropológica en un hospital psiquiátrico en las afueras de la Ciudad de México. Estas radios me parecieron una iniciativa maravillosa para el campo de la salud mental, y algo muy necesario para el caso de México, donde prácticamente la única opción para personas con sufrimiento mental es el encierro en un hospital psiquiátrico.

Lo que siguió a este descubrimiento fue una invitación a Alfredo Olivera, de radio La Colifata, a la Unidad Xochimilco de la Universidad Autónoma Metropolitana (UAM-X). La visita se concretó en el mes de octubre de 2008 y tuvo como propósito realizar una capacitación con miras a iniciar una experiencia parecida en México. Para el año 2009 ya estábamos listos para lanzar una iniciativa radiofónica dirigida a personas con sufrimiento mental. Habíamos conformado un equipo de trabajo con profesores, alumnos y recién egresados de la UAM-X.

Sin embargo, tuvimos dificultades para encontrar una institución de atención en salud mental que acogiera nuestra propuesta. Ante esta imposibilidad de encontrar un lugar donde alojar la radio, se decidió instalar Radio Abierta en la Universidad. Así fue como nació la primera radio en México realizada por personas con experiencias psiquiátricas: un 10 de junio de 2009, en uno de los jardines de la UAM-X.

\section{¿Qué significado tiene que Radio Abierta} esté en el campus de una universidad?

Fue una decisión que tomamos porque no tuvimos otra alternativa, pero sin duda fue muy acertada porque le imprimió una huella indeleble: se trataba de una iniciativa radiofónica de atención en el campo de la salud mental y de naturaleza comunitaria emplazada, precisamente, en una comunidad y no dentro de un hospital psiquiátrico.

Las personas con sufrimiento mental que participaban en esta experiencia lo hacian en el marco de una comunidad universitaria. Esto las habilitaba a establecer vínculos con estudiantes, incorporarse a las actividades culturales de la propia universidad (conciertos, cine, coro, biblioteca) y ser parte de una comunidad no psiquiátrica ni medicalizada. Asimismo, ser parte de una comunidad universitaria también hizo posible que Radio Abierta fuera incorporada como parte de la programación de la FM 94.1 UAM Radio, la estación radiofónica del centro.

A lo largo de los años también se hizo evidente que el hecho de que la comunidad universitaria esté en el ADN de Radio Abierta tuvo un impacto positivo en varios de los participantes. Algunos de ellos han retomado sus estudios universitarios truncos o han iniciado carreras universitarias, en la UAM-X y en otras instituciones educativas. Y otros más han encontrado nuevos trayectos biográficos posibles, más allá del circuito psiquiátrico.

¿Es posible reconocer algunas etapas en el proceso de consolidación de Radio Abierta, en estos ocho años de recorrido? ¿En qué estadio se encuentran en la actualidad?

Comenzamos con un dispositivo radiofónico grupal, que cada miércoles instalábamos en un jardín de la universidad: eran sesiones de tres horas de duración que registrábamos en audio. Con ese material se editaban microprogramas de diez minutos y cápsulas de entre tres y cinco minutos, que se reescuchaban en el marco del propio dispositivo. Era como un ejercicio de reconocimiento grupal e individual de esa especie de sonoridad humana que se producía en 
cada encuentro de los miércoles. Esta fue la primera etapa de Radio Abierta, en la que no hubo transmisión por ninguna plataforma comunicacional.

En una segunda fase, a partir del año 2011, comenzamos a transmitir un programa semanal a través de la estación radiofónica de la UAM. Era un programa que salía en vivo los miércoles y que fue muy importante para los participantes, no solo porque sus voces circulaban por la esfera pública, sino también porque, en paralelo a la transmisión en vivo, habilitamos las redes sociales (Facebook y Twitter) y eso les permitía establecer una comunicación y un vínculo con el mundo, con los radioescuchas. En la actualidad seguimos funcionando con este medio asociado que es la FM 94.1 UAM Radio, pero el programa es grabado en el jardín y transmitido en diferido cada miércoles, con retransmisión los sábados.

La tercera fase inició cuando a la radio le agregamos una revista digital denominada Toing, de aparición cuatrimestral, que publicó su primer número en octubre de 2011. Hasta la fecha han sido publicados diecisiete números en forma ininterrumpida. En esta revista publican materiales escritos e imágenes personas con sufrimiento mental de México, Argentina, Costa Rica, Portugal, Italia, Rusia, Francia, España. Son autores que, al mismo tiempo, son hacedores de radios por la salud mental en esos países.

En 2014 comenzamos también la producción de materiales audiovisuales, tales como videocampañas contra la discriminación y la producción de un video comunitario -realizado por los propios participantes de Radio Abierta desde el guion, la cámara y la edición- que se llama Luces, cámara, locura. Esa fue una nueva fase, en la que a la radio y a la revista digital le agregamos otro medio que es el audiovisual. Finalmente, desde el 2015 realizamos también streaming de radio desde nuestra propia plataforma web durante las 24 horas, todos los días de la semana.
En este breve recorrido intento dar cuenta de la complejización y multimedialidad que le hemos ido imprimiendo a la propuesta. Radio Abierta hoy es un hipermedio o un multimedio -transmisión por FM, streaming por Internet, revista digital, producciones audiovisuales-, y el gran reto que tenemos por delante es consolidar un devenir transmedia. En esa aventura estamos.

Desde esta experiencia, ¿cuáles son los desafíos que implica comunicar la diferencia?

Comunicar la diferencia es un desafío en sí mismo. Creo que no hay una única forma ni una receta universal para poder hacerlo. Pero, además, cuando hablamos de comunicar la diferencia en relación a la locura estamos enfrentando otros desafíos, más allá de los territorios de la comunicación en sí misma, que están vinculados a mecanismos sociales e institucionales de producción de silenciamiento social. Cómo comunicar la diferencia es algo que nos preguntamos todos los días en Radio Abierta.

No nos interesa comunicar una diferencia solipsista, una diferencia que se quede hablando sola. Apostamos por formas dialógicas y polifónicas de comunicarla, y por eso propiciamos que las voces de la locura resuenen, circulen y se mezclen con otras voces en la esfera pública. Queremos que la diferencia dialogue, negocie sentidos, ponga en entredicho verdades asumidas, que inaugure otras conversaciones públicas.

Tampoco nos interesa comunicar una diferencia envasada para que sea consumida y tragada como un producto más del marketing comunicacional. Por eso, a lo largo de todos estos años de Radio Abierta, nos cuestionamos mucho sobre cómo las formas de comunicar la diferencia también pueden ir naturalizándose, tanto para los participantes que hacen la radio como para el equipo de profesionales que acompañamos 


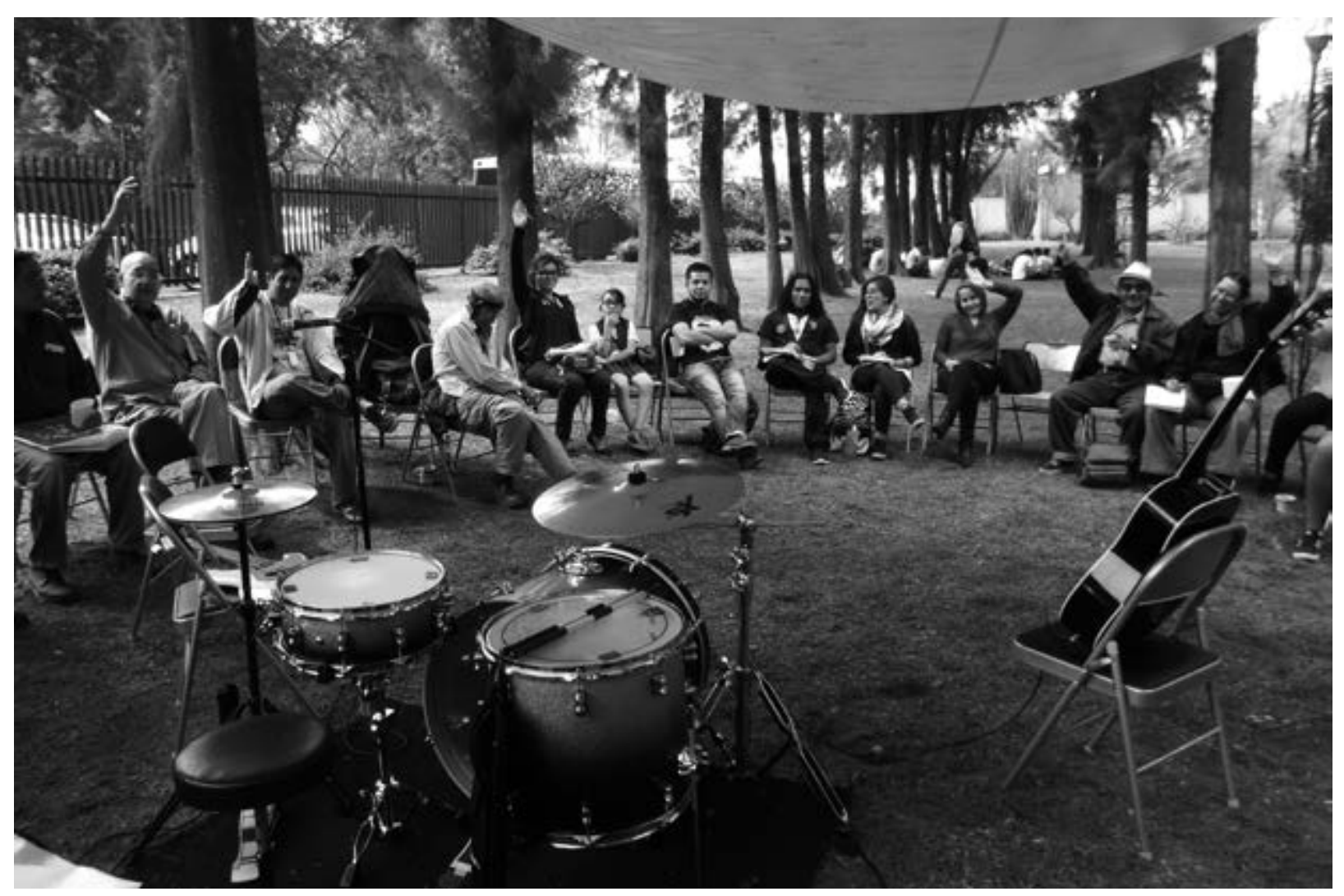

Foto: Radio Abierta

este proceso. Una diferencia estabilizada, normalizada, envasada, deja de ser diferencia. Deja de desestabilizar. Y esa es, precisamente, la potencia misma de la diferencia: la capacidad de subvertir.

Por eso, en Radio Abierta nos interesa comunicar la diferencia para hacer una diferencia: para romper estigmas, para desmantelar prejuicios, para desnivelar los territorios de la normalidad y la racionalidad, para hacer que en el mundo haya un lugar digno para todos.

¿Qué significa para los participantes vivir la experiencia de comunicar a otros y ser escuchados?

En diferentes momentos de los casi ocho años de existencia de Radio Abierta, y a través de diferentes modalidades -declaraciones a la prensa, entrevistas cualitativas y cuestionarios que aplicamos para dar seguimiento, entre otras- los participantes han contado lo que significa para ellos participar en esta experiencia de radio. Voy a retomar algunas de las ideas que ellos mismos han expresado.

En primer lugar, Radio Abierta es para ellos un espacio de escucha, de diálogo, de encuentro y de reconocimiento en tanto seres humanos. Como los interpelamos como personas - no asumimos ningún diagnóstico psiquiátrico- han encontrado en este espacio la posibilidad de reconectarse con sus propias vidas, con sus propios intereses y deseos, y retomar la posibilidad de estar en el mundo más allá (o más acá) de la colonización que produce vivir atrapado en un diagnóstico psiquiátrico. Por ejemplo, a partir de esta experiencia, algunos participantes han retomado actividades que habian quedado truncas con las crisis e internamientos, y absolutamente borradas con la etiqueta de "esquizofrénico" o "bipolar". Así, con el abrigo de la radio, han vuelto a tocar la guitarra, a 
escribir poemas, a pintar, a hacer amigos, a sentirse personas que pueden aportar a la sociedad desde su condición de diferencia.

En segundo lugar, y conectado con lo anterior, Radio Abierta significa para los participantes la posibilidad de que otros trayectos biográficos puedan ser esbozados desde una posición de sentirse parte de la sociedad. Es decir, se habilita otra cartografía, no psiquiátrica, para que puedan ser trazados otros itinerarios de vida: ser un locutor en una radio, un estudiante en una universidad, un poeta que publica un libro, un músico que graba su propio disco, un escritor que publica en la revista Toing o un periodista que hace una entrevista a un grupo de música para un programa que se transmite por streaming de radio.

Finalmente, Radio Abierta es también una comunidad de prácticas en la que los participantes intercambian saberes locales -sobre los padecimientos y las distintas maneras de estar en el mundo-, aprenden nuevas herramientas -a través de talleres de periodismo, de arte, de uso de nuevas tecnologías- y se vuelven agentes de cambio y de inclusión social.

Como antropóloga y testigo privilegiada de esta experiencia, ¿cuáles han sido los mayores aprendizajes en estos años?

Mi formación y trayectoria eran, hasta que inicié esta experiencia, estrictamente académicas. Era, retomando un concepto de Pierre Bourdieu, portadora de un habitus académico. Estudié sociología y realicé un doctorado en antropología, y me dediqué mucho tiempo a realizar investigación sobre la problemática de la exclusión social.
La experiencia de la radio me arrojó a otros territorios: me desarropó de muchas certezas disciplinarias, me obligó a despensar muchas categorías y conceptos, me desdibujó muchas fronteras, me desacomodó muchas herramientas metodológicas. Diría que, en todos estos años de Radio Abierta, he aprendido muchos desaprendizajes.

Al igual que a los participantes, esta experiencia también me habilitó otros tránsitos y otros trayectos. Uno de ellos es, sin duda, el de pensar y hacer en la encrucijada. En ese cruce de caminos donde las disciplinas tartamudean y donde el hacer es también político, porque subvierte un orden naturalizado de sentidos y experiencias. Radio Abierta me cambió la frecuencia. Tengo un habitus mutado y mutante. Me hizo sintonizar con la inexorable potencia de la vulnerabilidad humana.

\section{Sara E. Makowski Muchnik}

Doctora en Ciencias Antropológicas (UAMIztapalapa, México) y profesora e investigadora en la Universidad Autónoma Metropolitana (Unidad Xochimilco, México). Sus líneas de investigación abarcan la exclusión social, la cultura, la salud mental y la comunicación alternativa. Desde 2009 coordina Radio Abierta. Además de numerosos artículos en revistas especializadas, ha publicado los libros Jóvenes que viven en la calle (Siglo XXI, EditoresUAM-I, México, 2010) y Las flores del mal. Identidad y resistencia en cárceles de mujeres (Universidad Autónoma Metropolitana, México, 2010). 